\title{
EVOLUÇÃO DO CONSUMO DE COMBUSTÍVEL DO FORNO DE REAQUECIMENTO DE PLACAS DO LAMINADOR DE TIRAS A QUENTE DA USIMINAS*
}

\author{
Eduardo Amado Marconato ${ }^{1}$ \\ Sergio Funayama de Castro ${ }^{1}$ \\ Marcos Roberto Soares da Silva²
}

\section{Resumo}

No final do primeiro trimestre de 2012, a Usiminas iniciou a operação da nova linha de laminação de tiras a quente (LTQ2) na Usina de Cubatão visando fornecer bobinas de aço para a indústria automotiva, do petróleo e gás, máquinas agrícolas, aplicações diversas de aços estruturais, entre outras. A busca pela excelência na qualidade dos produtos e melhoria contínua nos processos estende-se a todos os setores da Usiminas como fatores de manutenção e ampliação da competitividade no mercado. Um dos principais itens que impactam o desempenho da produção na laminação a quente é o consumo de combustíveis para reaquecimento das placas até a temperatura adequada ao processo na linha de laminação. Desde o start up do laminador, o desempenho do forno de reaquecimento vem apresentando evolução expressiva em relação ao consumo de combustíveis. Essa evolução deveu-se especialmente à otimização dos parâmetros de controle e às melhorias alcançadas no processo. Foi alcançada uma redução média superior a $25 \%$ no consumo específico de combustível, quando comparado ao início da produção comercial do laminador.

Palavras-chave: Forno de reaquecimento; Laminação a quente; Consumo específico de combustível.

\section{FUEL CONSUMPTION PERFORMANCE OF REHEATING FURNACE FROM USIMINAS HOT STRIP MILL PLANT}

\begin{abstract}
During the first quarter of 2012, Usiminas has started the new hot strip mill (LTQ2) in Cubatão in order to provide steel coils for automotive industry, oil and gas, agricultural machinery and structural steels. The continuous improvement of processes, quality and cost reduction extends to every company that desires to keep competitive in the global market. One of the major factors that impact directly the production costs in hot rolling mills is the fuel consumption responsible to reheating slabs until the temperature required to be processed by finishing mills. Since the start up, the performance of reheating furnace has a very significant reduction of specific fuel consumption as reference the nominal performance established by supplier, due especially to control parameters optimization and process improvements, allowing an overall reduction of specific fuel consumption higher than $25 \%$ since the beginning of commercial production.
\end{abstract}

Keywords: Slab reheating furnace; Hot strip mill; Specific fuel consumption.

1 Engenheiro de Materiais, Mestre em Engenharia de Materiais, Engenheiro de Produção, Laminação a Quente, Usiminas, Cubatão, São Paulo, Brasil.

2 Engenheiro Metalurgista, Gerente Suporte Técnico, Laminação a Quente, Usiminas, Cubatão, São Paulo, Brasil. 


\section{INTRODUÇÃO}

No processo de laminação a quente, uma das etapas mais significativas é o reaquecimento do material até a alcançar temperaturas ideais para a etapa de laminação, garantindo boa conformabilidade do aço e uniformidade de temperatura para solubilização dos elementos de liga para obtenção dos requisitos mecânicos e metalúrgicos dos produtos laminados. O atendimento desses requisitos deve ser alcançado através de um menor custo de processamento possível, buscando melhoria contínua na produtividade e menor consumo energético, sendo este último um dos principais fatores que impactam diretamente no custo de produção da laminação a quente.

O consumo de energia térmica, o perfil de aquecimento objetivado até a temperatura de extração da placa e o controle da atmosfera durante o aquecimento do material dentro do forno estão intimamente ligados à qualidade dos produtos para o atendimento aos requisitos exigidos pelos clientes. Desta forma, energia térmica despedida durante o aquecimento está relacionada à competitividade da empresa através do custo final por tonelada produzida de bobina. A economia energética tem que ser perseguida através obter o ponto de equilíbrio entre melhor produtividade do processo e a melhor homogeneização da temperatura do material a ser laminado [1]. Segundo Teixeira, o forno de reaquecimento é responsável por $15 \%$ do consumo total de combustível numa usina siderúrgica integrada [2].

Desde o startup do laminador no final do primeiro trimestre de 2012, o desempenho do forno de reaquecimento apresenta uma evolução bastante expressiva na redução do consumo de combustível visando como meta o valor de desempenho estabelecido pelo fornecedor do equipamento, maximizando os recursos disponíveis para o cumprimento almejado por meio da otimização dos parâmetros de controle, melhoria contínua no processo e da matéria prima. Desta forma a Usiminas fortalece sua posição no mercado de laminados a quente através do enobrecimento do mix de produtos e melhor competitividade em custos de produção.Este trabalho tem como objetivo apresentar as principais atividades desenvolvidas para otimização do processo de laminação visando a redução do consumo específico do forno de reaquecimento de placas e aumento de produtividade do laminador.

\section{MATERIAIS E MÉTODOS}

A nova linha de laminação a quente conta com um forno de reaquecimento de placas tipo walking beam (vigas caminhantes), com capacidade nominal de $400 \mathrm{t} / \mathrm{h}$, totalmente automatizado com modelamento matemático para controle de combustão denominado FlexyTech Model utilizado para otimização do aquecimento e consequente redução do consumo de combustível. Além de contar com tecnologia inédita na Usiminas de combustão do tipo flameless (sem chama), onde o regime de combustão é caracterizado pela ausência de chama de pré-mistura, garantindo melhor uniformidade de temperatura interna da câmara de combustão. A figura 1 apresenta as principais características do forno de reaquecimento de placas do LTQ2 [3].

O modelo de reaquecimento é realizado dinamicamente de maneira online cujo principal objetivo é realizar o cálculo da distribuição de temperatura em cada placa no interior do forno. Isso é conseguido através da solução de equações matemáticas complexas, denominadas equações diferenciais de Fourier, que calculam a distribuição de aquecimento das placas dentro do forno. 
O modelo matemático comanda o sistema de controle de nível 2 com as temperaturas visadas no forno em função ritmo de desenfornamento médio do material, onde então o controle lógico realiza o cálculo do valor das temperaturas objetivadas de todas as zonas de aquecimento, através da resposta do modelo da temperatura calculada de cada placa, prevendo o atendimento da temperatura visada da placa no final de cada fase do forno. O objetivo do controle lógico é reaquecer cada placa dentro do forno assim que a temperatura de extração for atingida e um ótimo consumo de energia seja atingido ao mesmo tempo.

Toda análise relacionada ao consumo específico de combustível do forno foi realizada através da compilação dos dados extraídos de banco de histórico do laminador desde a produção em escala comercial até o primeiro trimestre de 2015 . A análise será focada basicamente nas principais linhas de atuação realizada para a redução do consumo de combustível e aumento da produtividade do laminador, podendo ressaltar o aumento da taxa de ocupação dos fornos, redução da temperatura média de extração, tempo de permanência e participação do enfornamento a quente.

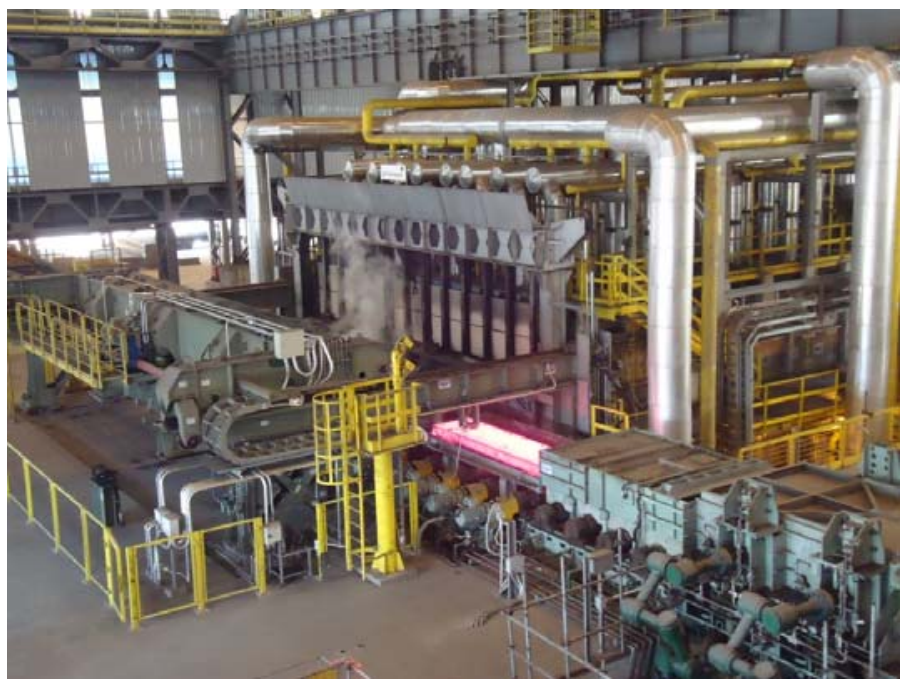

\author{
Fabricante \\ LOI Italimpianti \\ Capacidade Nominal \\ $400 \mathrm{t} / \mathrm{h}$ \\ Tipo Movimentação \\ Walking Beam \\ Dimensão \\ 12.300 x $57.200 \mathrm{~mm}$
}

Tipo Combustível

Gás Coqueria / Gás Alto Forno /

Gás Natural / Gás Aciaria

Figura 1. Forno de reaquecimento de placa da Usiminas Cubatão.

\title{
3 RESULTADOS E DISCUSSÃO
}

Desde a partida do laminador o consumo específico de combustível apresentou queda acentuada até o final do quarto trimestre de 2013 onde foi alcançado o melhor resultado histórico, ficando aproximadamente $11 \%$ do valor obtido durante a etapa de testes de performance do forno, onde as condições de avaliação foram rigidamente controladas, visando atingir a produtividade nominal especificada pelo fornecedor do equipamento, sem interferências usais de processo que ocorrem em uma linha de tiras a quente, como por exemplo a diversidade de largura e espessura do produto no programa de laminação, requisitos metalúrgicos restritos determinados pelo cliente, perfis de aquecimento diferenciados para cada material. A figura 2 apresenta evolução do consumo específico de combustível médio do forno de placas desde o início da laminação em escala comercial no LTQ2. 


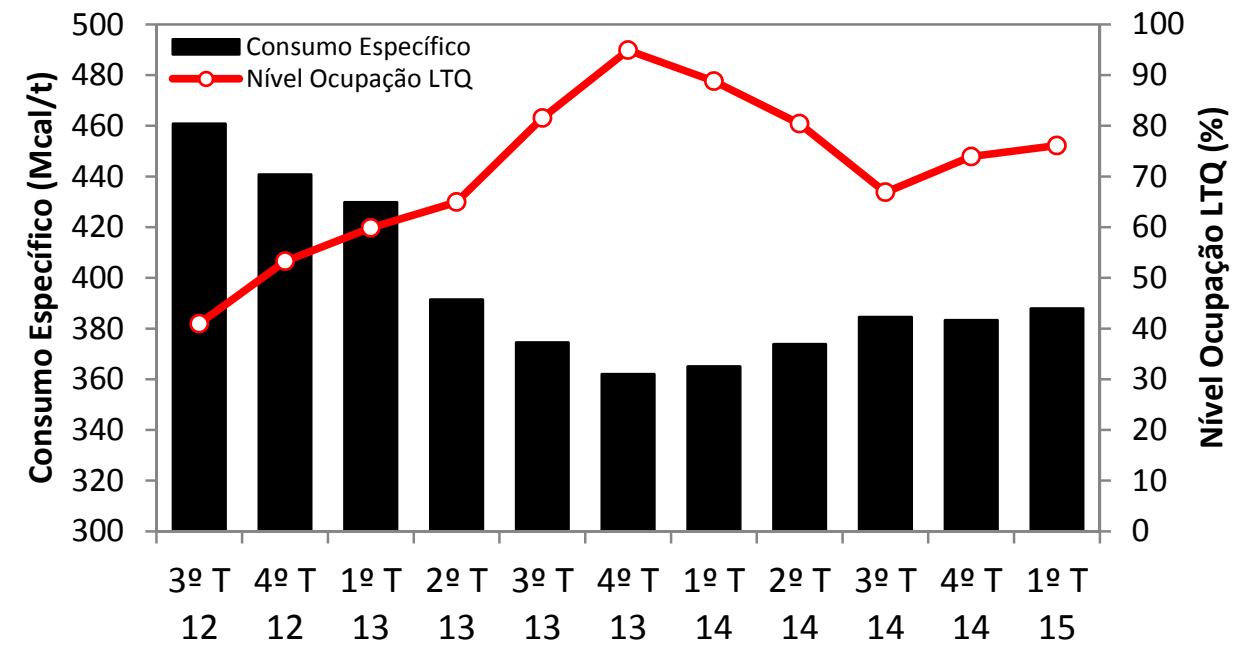

Figura 2. Evolução do consumo específico de combustível médio do forno de placas.

Com a possibilidade de aumentar o portfólio de produtos devido a um maior nível de automação e controles de processo no novo laminador, a participação de materiais que demandam maiores tempos de permanência e temperaturas de extração diferenciadas aumentou significativamente até o presente momento, atingindo patamar superior a $30 \%$ na mistura, impactando na produtividade média do forno e consequentemente do laminador, uma vez que na fase atual de expansão do laminador é contemplado somente um forno de aquecimento. Desta forma, tornando ainda mais desafiador a redução do consumo de combustível e aumento da competitividade dos produtos laminados em Cubatão. Na figura 3 é apresentação a participação de materiais de produtividade restrita do forno.

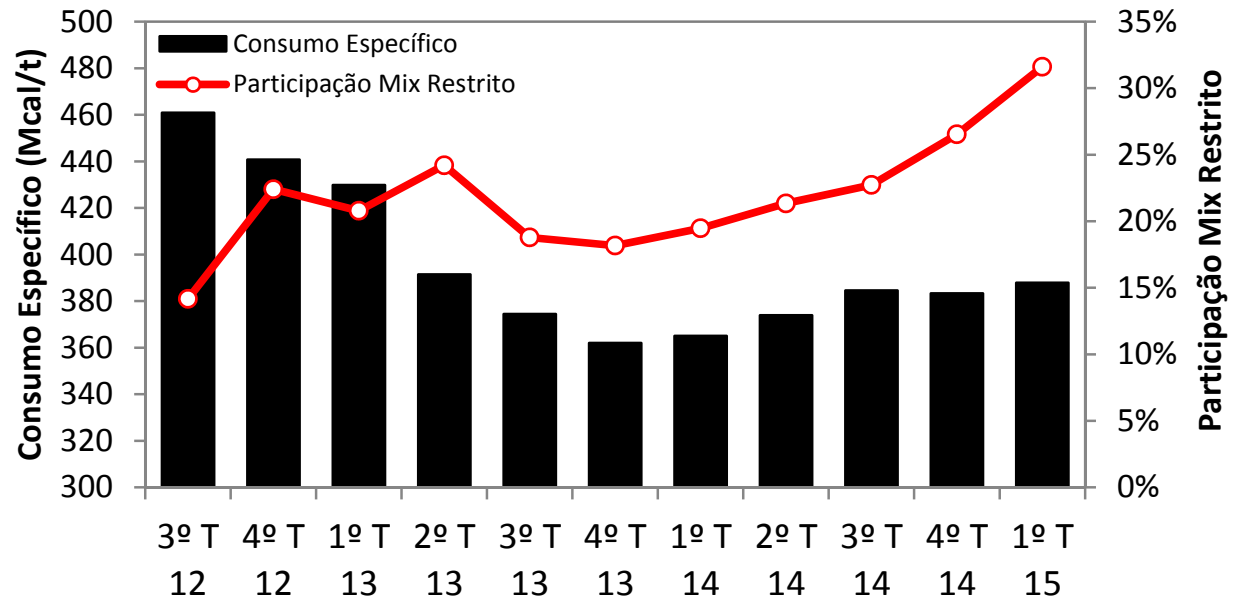

Figura 3. Participação de mix restrito.

O trabalho de otimização dos parâmetros de forno para todas as famílias de aquecimento vêm sendo intensificado desde 2013 até o presente momento, com estudos aumento da taxa de ocupação do forno, redução de tempo permanência, otimização do perfil de aquecimento, diminuição de temperatura de extração, melhora na qualidade dos programas de laminação. A seguir são apresentadas as 
três principais frentes de trabalho que foram desenvolvidas visando otimizar o processo de laminação, especialmente no que se refere ao consumo específico de combustível.

\section{1 Índice de Ocupação Forno}

O índice de ocupação do forno ou também conhecido como taxa ou área de cobertura é um parâmetro controlado no processo de laminação, pois esta intimamente ligado ao consumo de combustível, pois corresponde à utilização da área útil para realizar o reaquecimento da carga enfornada durante todo período que o material permanecerá dentro do forno. Desde 2012, houve uma concentração muito grande de estudos técnicos nas tabelas que delimitam o comprimento máximo permitido por dimensional de produto, visando aumento de produtividade do laminador e consequente redução de consumo de energia, principalmente após o término da etapa de Hot Test do laminador. O índice de ocupação atual esta ligeiramente acima de $80 \%$ como pode ser observado na figura 4 , devido principalmente a restrições de peso cliente e em alguns casos faixas dimensionais críticas, mesmo utilizando do recurso das linhas posteriores para divisão de bobinas para adequação da faixa de peso do cliente final.

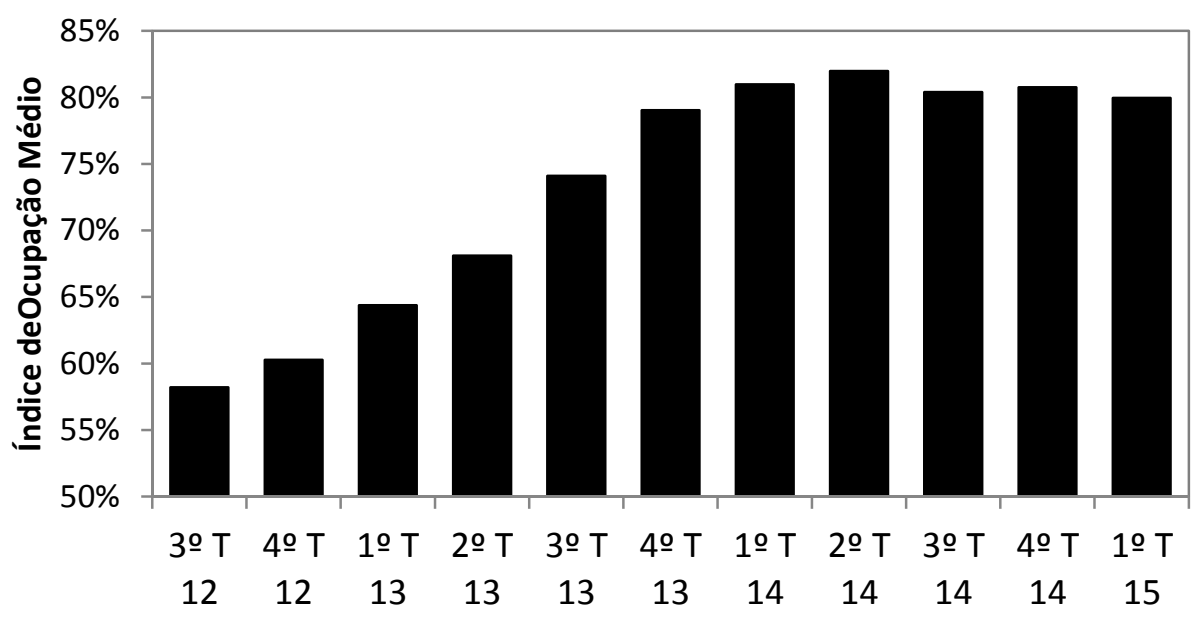

Figura 4. Evolução do índice de ocupação média do forno de placas.

Na figura 5 é possível observar a influência direta entre o índice de cobertura do forno e consumo específico de combustível correspondente, ou seja, quanto maior a ocupação da área útil do forno melhor será sua eficiência térmica para realizar o reaquecimento da carga enfornada. Para efeitos comparativos é apresentado no gráfico de forma diferenciada o valor de referência de consumo específico de combustível para uma condição operacional considerada como "ideal" que foi alcançada utilizando como índice de ocupação de $90 \%$.

Valores acima de $90 \%$ de ocupação no forno são usualmente praticados em função do comprimento máximo de placa projetado, porém a influência da faixa de peso de cliente e outros fatores externos ao forno acabam impactando na queda na área de cobertura média. Analisando os casos de menor consumo específico em função do índice de cobertura, pode se estimar a influência entre esses dois indicadores através da determinação uma linha teórica, identificada no gráfico como "Linha Teórica", não levando em consideração fatores de influência direta no consumo 
como a participação de mistura restrita. Desta forma teriamos um valor médio de redução de 3,4 Mcal/t para ponto percentual de área coberta.

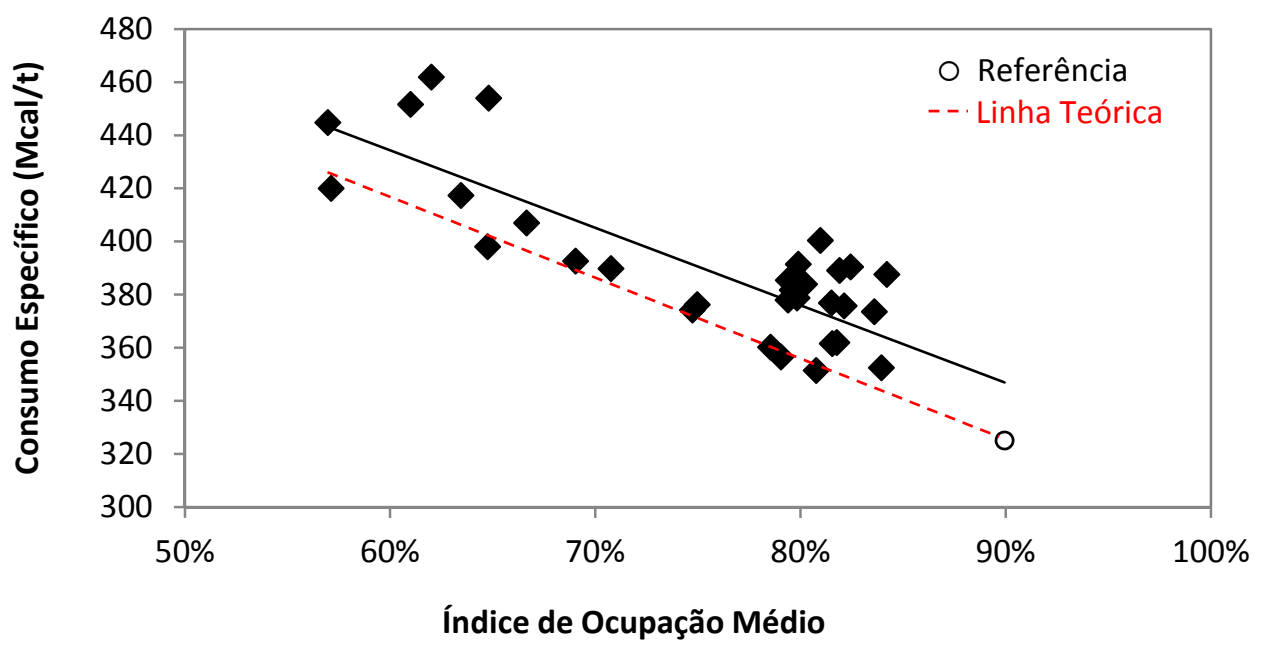

Figura 5. Influência índice de ocupação no consumo específico de combustível.

\subsection{Produtividade Média}

Segundo Holweg, o termo produtividade é resultado da melhoria nas operações de um sistema de produção enxuto, onde esta abordagem foi relacionada com "Sistema Toyota de Produção" como benchmarking para as organizações medir suas eficiências [4]. Este item está diretamente relacionado com o consumo de combustível do forno de placas, pois mede o volume de material desenfornado ou laminado por hora. Muitos fatores influenciam neste indicador, pois leva em consideração parâmetros gerais como o peso médio de placa, o comprimento de placa médio, tempo de permanência do material e o tipo de programa de laminação. Desde o início da produção no LTQ2, a participação de materiais mais restritivos mecânica e metalurgicamente cresce a cada novo trimestre em função do mercado consumidor da Usiminas, tornando a busca por alternativas mais eficientes cada vez maior, como podemos observar no gráfico 6. Conforme já mencionado anteriormente, mais de $25 \%$ do mix laminado a partir do $4^{\circ}$ trimestre de 2014 é composto por materiais que demandam maior tempo de forno, consequentemente há uma queda no valor de produtividade média do forno de placas.

A produtividade do forno de placas afeta diretamente no consumo específico de combustível, pois no caso dos materiais que demandam maior tempo de forno, acabam consumindo maior quantidade de energia térmica por tonelada produzida. Desta forma, a relação observada entre produtividade e consumo pode ser interpretada em escala potencial, conforme mostrado na figura 7.

A produtividade do forno de placas afeta diretamente no consumo específico de combustível, pois no caso dos materiais que demandam maior tempo de forno, acabam consumindo maior quantidade de energia térmica por tonelada produzida. $A$ produtividade média do laminador é de $303 \mathrm{t} / \mathrm{h}$ para um mix de material restrito em torno de $20 \%$, resultando assim em um consumo médio de $374 \mathrm{Mcal} / \mathrm{t}$. Em termos comparativos temos uma redução 16 Mcal/t para cada 10t/h acrescida na produtividade. 


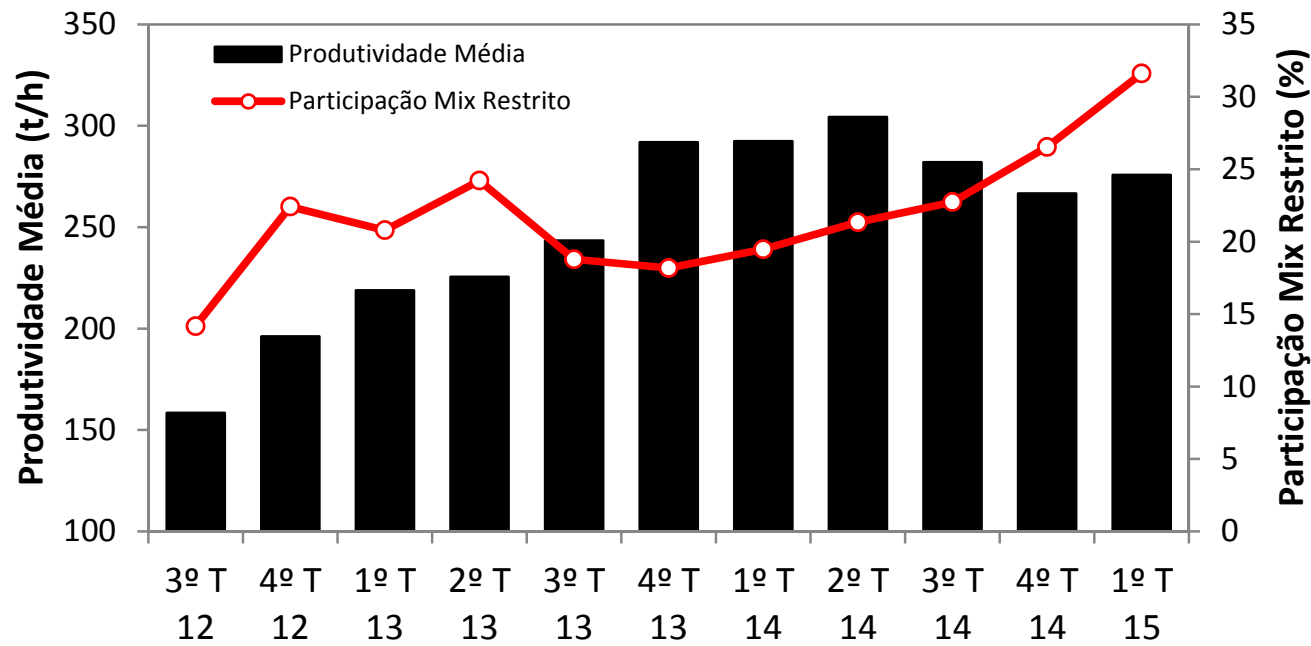

Figura 6. Evolução da produtividade média do forno de placas.

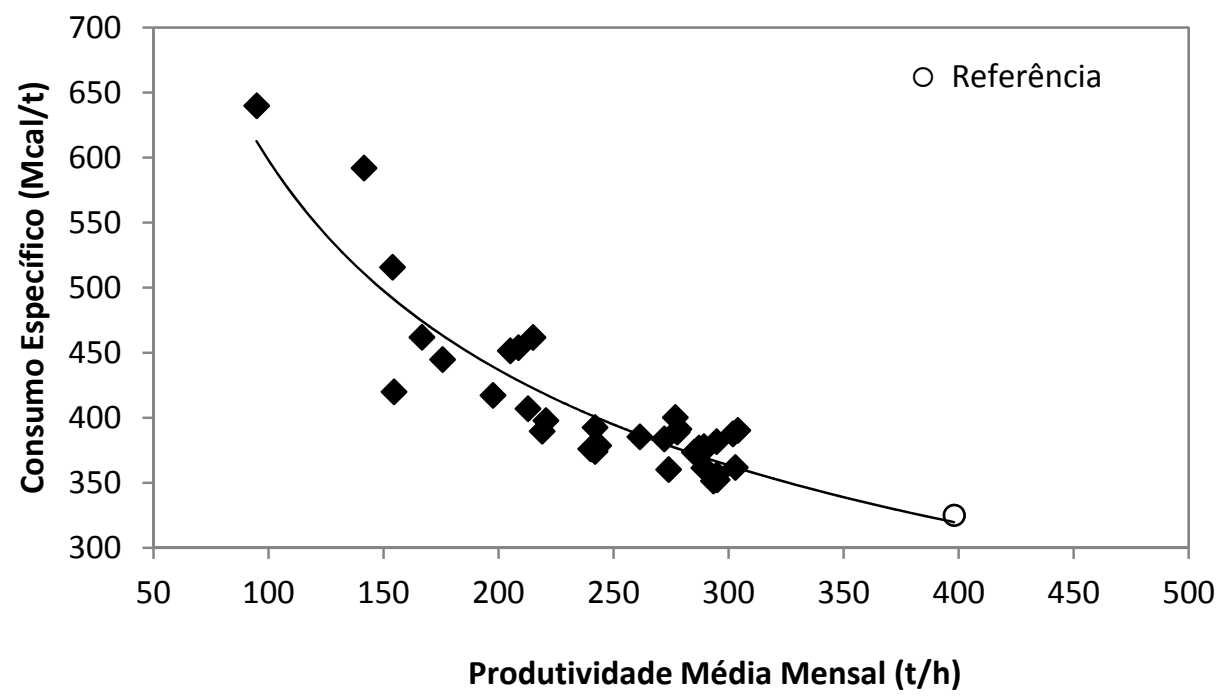

Figura 7. Influência da produtividade média no consumo específico de combustível.

\subsection{Overlapping}

Overlapping é um indicador de produção que foi implantado recentemente na linha de laminação a quente visando medir o nível de interferência entre os tempos permanência padrão das placas programadas em uma sequência de laminação. $O$ valor medido corresponde a porcentagem de perda média da carga com tempo de permanência maior da placa crítica que comanda o ritmo de extração e o aquecimento da carga enfornada como um todo, ou seja, quanto menor $o$ overlapping, menor a influência do tempo de aquecimento "extra" que a carga enfornada teve que permanecer dentro do forno.

Como pode ser esperado, quanto menor o grau de interferência entre os tempos de permanência objetivados em um mesmo programa de laminação, melhor para eficiência enérgica e produtividade do forno. Desta forma, este indicador é muito útil para medir a qualidade de programação com foco específico em produtividade. 


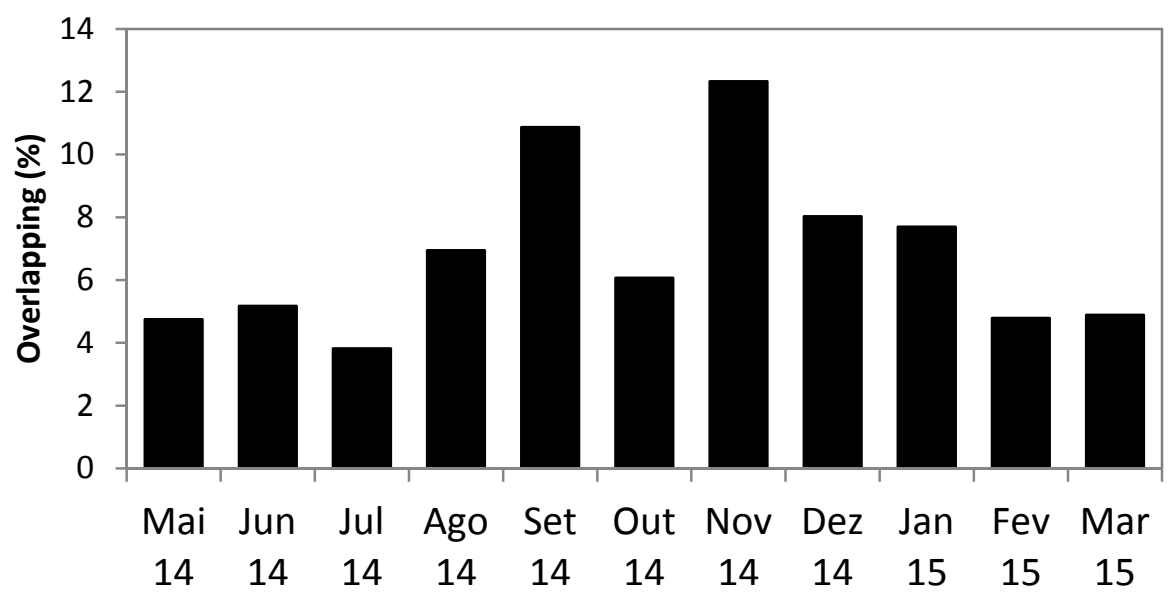

Figura 8. Evolução do indicador de overlapping.

\section{CONCLUSÃO}

Este trabalho teve como objetivo apresentar as principais atividades desenvolvidas para otimização do processo de laminação visando a redução do consumo específico do forno de reaquecimento de placas e aumento de produtividade do laminador. O maior benefício alcançado com as várias frentes de trabalho permitiu uma evolução contínua no consumo específico de combustível, chegando a $27 \%$ de redução, além do aumento da taxa de ocupação do forno, produtividade média e redução da interferência por overlapping.

\section{Agradecimentos}

Supervisores de turno, técnicos operacionais e operadores da laminação a quente da Usiminas Cubatão pelo suporte e companheirismo dados durante a execução dos trabalhos. Todo o corpo técnico das áreas de programação e energia e utilidades que colaboram para o êxito do trabalho, promovendo a sinergia entre as áreas.

\section{REFERÊNCIAS}

1 Marconato EA, Coscia FP, Guia JRP, Silva MRS. Redução do consumo de combustíveis dos fornos de reaquecimentos de placas da Usiminas Cubatão. $47^{\circ}$ Seminário de Laminação - Processos e Produtos Laminados e Revestidos, Belo Horizonte. Out. 2010.

2 Teixeira, MH, Jota, FG, Carmo, RA, Oliveira, CAS. Aplicação de controle avançado nos fornos de reaquecimento de placas da linha de tiras a quente da Usiminas. Tecnologia em Metalurgia e Materiais, São Paulo, v.4, n.1, p. 30-35, jul.-set. 2007.

3 Magalhães, MM, Marconato EA, Guia JRP, Silva MRS. Novo laminador de tiras a quente da Usiminas Cubatão. $47^{\circ}$ Seminário de Laminação - Processos e Produtos Laminados e Revestidos, Belo Horizonte. Out. 2010.

4 Holweg M. The genealogy of lean production. Journal of Operations Management, v.25, n.2, p.420-437, 2007. Disponível em: http://dx.doi.org/10.1016/j.jom.2006.04.001. 